\title{
O NOVO PERFIL E AS DIFICULDADES DO GESTOR DE RECURSOS HUMANOS
}

\author{
https://dx.doi.org/10.48097/2674-8673.2021n4p12
}

\author{
Flávia Moraes Coelho da Silva ${ }^{1}$ \\ Jaquicele Melo da Silva ${ }^{2}$ \\ Rejane de Araujo Nascimento ${ }^{3}$ \\ Eronildo Ferreira do Carmo ${ }^{4}$ \\ João Biron de Oliveira Filho ${ }^{5}$
}

\section{RESUMO}

A Gestão de Recursos Humanos está inserida nas organizações como meio de adequar as atividades realizadas com o desempenho pessoal dos indivíduos que as compõem. Algumas empresas tratam as pessoas como recursos, utilizando delas o máximo proveito possível, enquanto outras as tratam como patrimônio intelectual, as quais contribuem com seus conhecimentos. É possível verificar que o fator humano hoje é mais valorizado e este setor procura interligar os demais setores das organizações, buscando formas para termos como meta a valorização pessoal, pois assim o resultado será a qualidade dos serviços prestados no mercado. Este trabalho visa mostrar o novo perfil do profissional de RH no mercado, além da sua importância para o bom desempenho das organizações.

Palavras-chave: Gestão de pessoas. Organização. Perfil profissional. RH.

Data de submissão: 07/10/2020

Data de aprovação: 29/10/2020

\begin{abstract}
Human Resources Management is inserted in organizations as a means of adapting the activities carried out with the personal performance of the individuals that compose them. Some companies treat people as resources, using them as much as possible, while others treat them as intellectual assets, which contribute their knowledge. It is possible to verify that the human factor today is more valued and this sector seeks to interconnect the other sectors of

1 Concluinte do Curso de Pós-graduação de Gestão em Psicologia Organizacional e do Trabalho da FMGR.

E-mail: flaviamoraes8651@gmail.com

2 Concluinte do Curso de Pós-graduação de Gestão em Psicologia Organizacional e do Trabalho da FMGR.

E-mail: jaquicele2010@live.com

3 Concluinte do Curso de Pós-graduação de Gestão em Psicologia Organizacional e do Trabalho da FMGR.

E-mail: rejane_23@yahoo.com.br

4 Professor da Faculdade Metropolitana da Grande Recife e coorientador do artigo.

E-mail: proferon100@gmail.com

5 Professor da FMGR. Coordenador do Curso de Gestão em Psicologia Organizacional e do Trabalho.

Orientador do artigo. E-mail: joaobiron@gmail.com
\end{abstract}


organizations, looking for ways to have personal valorization as a goal, as this will result in the quality of services provided in the market. This work aims to show the new profile of the HR professional in the market, in addition to its importance for the good performance of organizations.

Keywords: People management. Organization. Professional Profile. HR.

\section{INTRODUÇÃO}

O gestor de Recursos Humanos tem características de influência, participação, liderança e motivação, porém na maioria das vezes as empresas só priorizam a capacidade de ter resultados através das pessoas, bem como atribuem outras atividades obtendo um perfil de $\mathrm{RH}$ generalista, sem oferecer suporte e autonomia. Em alguns casos gestores são influenciados pelo clima organizacional da instituição que pode ser modificado ou influenciado p or algum gestor que cria situações em que nos perguntamos de que adianta termos a tecnologia se não conseguimos gerir as pessoas de uma maneira eficiente e prepará-las para exercer com responsabilidade e qualidade sua função. Dessa forma questionamos: quais os desafios enfrentados pelo gestor de recursos humanos?

A pesquisa sobre o profissional de $\mathrm{RH}$ é importante porque a nova geração de funcionários que habita a maioria das organizações está cada vez mais competitiva. Vale afirmar que o colaborador nunca foi tão importante quanto é hoje. Dessa forma, pessoas valorizam e concorrem para um ambiente harmônico de trabalho que significa maior produção efetiva da empresa, afinal, adquirir conhecimentos está cada vez menos limitado e cada vez mais espalhado por outros setores que muito têm a contribuir para a aprendizagem para toda a vida, portanto, o estudo constata que o comportamento do colaborador se relaciona com ações integradas e fundamentais de RH. Sendo assim, um novo olhar do setor e a sua inclusão no planejamento estratégico sob uma nova perspectiva irá interferir na postura dos seus funcionários e torná-los profissionais mais eficientes e eficazes.

As organizações precisam de pessoas para existir. Lidar com elas é uma das principais funções dos gestores. Entretanto, hoje, esse processo ficou mais prático para que uma empresa tenha sucesso e se destaque. Isso ocorre devido às exigências que atualmente são feitas, diferente do passado. Além disso, as atividades pedem menos trabalho braçal, mais capacidade de inovação e entendimento. Atualmente é necessário ter mais criatividade e conhecimento do que a força física. Dessa maneira temos um novo tipo de profissional que está sendo mais acionado pelo mercado com capacidade e outras necessidades e desejos. $\mathrm{O}$ mercado para o profissional de Recursos Humanos tem alcançado grande importância para as 
empresas nos últimos anos. Está cada vez mais claro que uma empresa que faz boa gestão torna seus colaboradores mais produtivos. Com a valorização, vieram melhores salários e uma busca por maior qualificação dos profissionais com maior capacidade de trabalhar em grandes departamentos de RH.

O profissional de RH tem importantes funções no Departamento Pessoal de uma empresa, dependendo da área para a qual é contratado. Ele é responsável por coordenar, selecionar e orientar colaboradores a fim de contribuir com os objetivos da organização para a qual trabalham, além de auxiliar no desenvolvimento e motivação dos trabalhadores.

O gestor de RH também lida com estratégias, técnicas de treinamento e seleção. Segundo Schikmann (2015, p.10):

(...) estamos vendo a transformação da área de Recursos Humanos sair de uma posição reativa e preocupada com aspectos de controle e papelada (o Departamento de Pessoal), passando por um setor de RH mais preocupado com a motivação, com o clima organizacional e os aspectos de liderança (Gestão de Pessoas) até chegar a um setor de Recursos Humanos preocupado com o atingimento dos objetivos estratégicos da organização (Gestão de Pessoas).

É possível observar que mudanças são inevitáveis, porém o profissional de Recursos Humanos hoje é bem mais valorizado que antes e passa a funcionar com a função de suporte, responsável pelo desenvolvimento contínuo de uma organização. Assim, as pessoas se tornam mais exigentes com relação ao trabalho. Suprir somente suas necessidades passa a não ser mais suficiente.

De acordo com o pensamento de Chiavenato (2010, p. 4):

(...) as organizações são como seres vivos e, sendo bem sucedidas, podem crescer ou apenas sobreviver. Se ela cresce há um aumento de recursos para que opere bem como um aumento de pessoas necessárias à manutenção do negócio e fazer com que os recursos materiais sejam utilizados de forma eficiente. As pessoas tornam-se o diferencial na promoção do sucesso da empresa.

Este estudo tem como objetivo identificar o novo perfil do profissional de Recursos Humanos em um novo tempo, assim como demonstrar a importância desse indivíduo dentro das organizações, trabalhando em prol da valorização dos colaboradores e, consequentemente, do desenvolvimento da instituição.

\section{FUNDAMENTAÇÃO TEÓRICA}

Este trabalho se inicia esclarecendo sobre a função de liderar dos gestores nas organizações, a sua importância na coordenação dos departamentos da empresa, a contribuição deles no crescimento da organização, além de atuar na motivação, capacitação e desenvoltura profissional dos colaboradores. 
Uma publicação no Portal RH (rhportal.com.br) em setembro de 2015 já chamava a atenção para o novo perfil desse profissional. Oliveira (2015) afirma que há uma metamorfose geral. A economia mudou, a administração mudou, a política mudou, as pessoas mudaram, enfim, tudo mudou. Assim, o profissional de Gestão em Recursos Humanos também deve mudar. O mercado também trabalha com mudanças, buscando profissionais que possuam características generalistas, absorvendo mais atribuições, exigindo também capacitação constante, aproximação com as lideranças e suas equipes, permitindo ao profissional um trabalho mais completo e complexo no desenvolvimento do capital humano.

Outro artigo publicado no site Xerpa (xerpa.com.br) tem ideia similar, descrevendo que a tendência do novo mercado tem um olhar diferente para esses profissionais, saindo da esfera de resolução de assuntos burocráticos para uma posição mais estratégica na organização. Segundo o artigo, esses profissionais têm função estratégica, atuando diretamente na manutenção do clima organizacional e da motivação das equipes. São eles que garantem mais produtividade e bons resultados para o negócio, sem deixar de lado o bem-estar dos colaboradores.

\section{METODOLOGIA}

Com o propósito de esclarecer sobre a importância do processo do profissional de RH dentro das organizações, foi realizada uma pesquisa utilizando como técnica a consulta bibliográfica, sendo esta baseada em teóricos que descrevem em suas obras assuntos relacionados ao tema.

$\mathrm{Na}$ pesquisa de campo foram utilizados questionários com perguntas abertas e de múltipla escolha para um grupo de 12 funcionários de uma empresa pernambucana que atua no segmento comercial com lojas em todo o Nordeste. A pesquisa foi realizada em uma das lojas da rede localizada na cidade de Jaboatão dos Guararapes-PE. Foi mantido o sigilo da empresa por questões éticas e ausência de autorização para tal exposição.

Dos 12 colaboradores questionados foram obtidas nove respostas válidas. Os participantes evitaram direcionar ou influenciar as escolhas. $\mathrm{O}$ resultado obtido deve refletir o retrato da empresa, sendo divulgado ao responsável pela organização, já com a proposta sugerida para o plano de ação. 


\section{RESULTADOS DA PESQUISA}

A seguir são apresentadas as questões relativas ao questionário distribuído aos participantes da pesquisa, assim como a reprodução da leitura do gráfico de cada pergunta.

\section{Qual a estrutura do RH da sua empresa?}

9 respostas

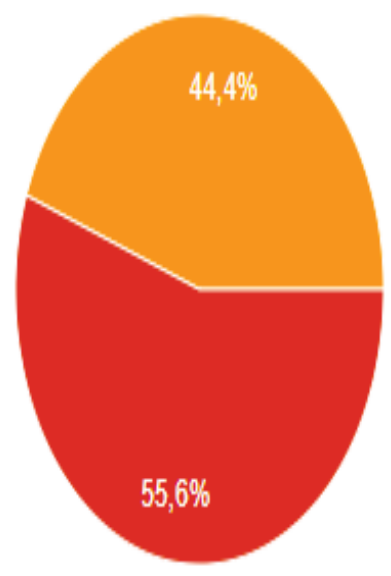

Existe um profissional para cada departamento, RH, DP e ADM

$0 \mathrm{RH}$ tem perfil generalista, assumindo RH, DP e ADM

Acho o RH muito ausente, não consigo perceber atuação

É interessante observar que a maioria dos participantes percebe o RH com perfil generalista, como o mercado requer hoje, mas ao mesmo tempo um número bem expressivo aponta para a ausência de atuação deste departamento.

\section{Como você acredita que deve ser a atuação do RH atualmente?}

Em relação a esta questão aberta, de uma forma geral, os entrevistados responderam que o setor de RH tem função estratégica na empresa, não ficando apenas com a obrigação de selecionar, contratar e treinar, mas promover capacitação contínua, primando pela valorização dos colaboradores e proporcionando um ambiente de trabalho agradável. 


\section{O RH da sua empresa desenvolve a liderança?}

9 respostas

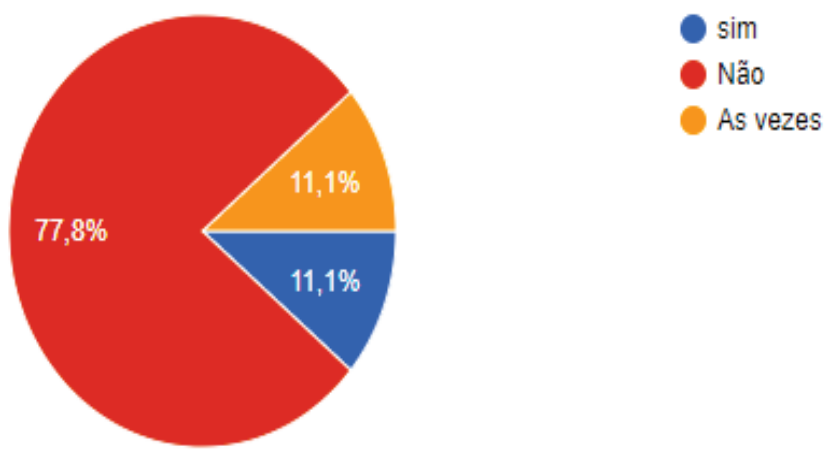

Como é possível observar no gráfico, a grande maioria dos entrevistados não percebe o desenvolvimento da liderança dentro da empresa ao passo que tal fato é visível apenas para uma minoria.

\section{Em sua opinião, quais as dificuldades que o RH enfrenta na sua empresa?}

9 respostas

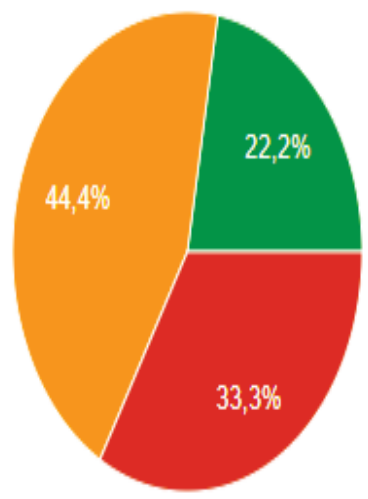

Falta de autonomia

Percebo que não existe o interesse por parte do RH, em buscar as melhorias para os colaboradores

Acumulo de atividades sem suporte necessário

Deve existir dificuldades, porém não percebo de forma explícita.

Para a maioria dos entrevistados (44,4\%), o acúmulo de atividades sem o suporte necessário mostra-se como dificuldades enfrentadas pelo setor. Para 33,3\% dos entrevistados, parece não haver, por parte do setor, o interesse em buscar melhorias. 22,2\% dos participantes alegam que pode haver dificuldades, mas não são capazes de reconhecê-las. 


\section{Como está a comunicação do RH com os colaboradores e gestores da sua empresa?}

9 respostas

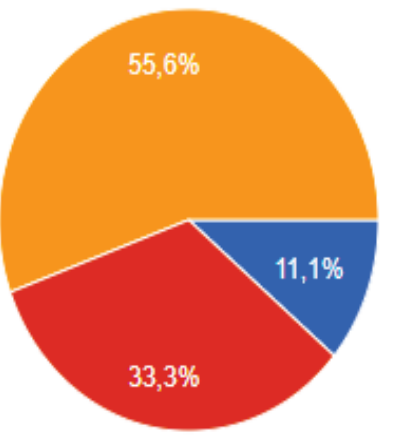

Sempre são realizadas reuniões e treinamentos, aproximando os setores

Os lideres trabalham a sua maneira, 0 RH não intervem

Não percebo comunicação, só informativos nos quadros de aviso

Para essa indagação, a maioria $(55,6 \%)$ respondeu não haver comunicação explícita entre o RH e os diversos setores, a não ser por intermédio de informativos e quadros de avisos. 33,3 dizem que os líderes trabalham ao seu modo, sem interferência do RH, e 11,1\% afirmam haver reuniões e treinamentos com a finalidade de aproximar os setores.

\section{Como é realizado o processo seletivo na sua empresa?}

9 respostas

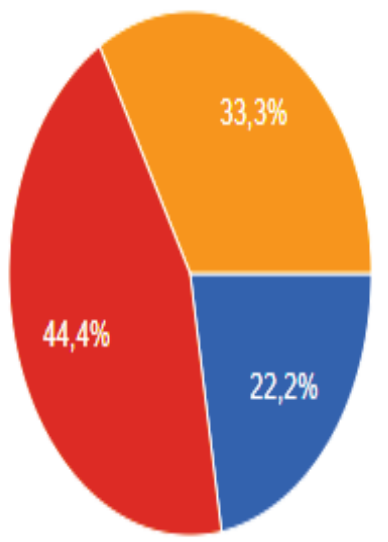

É bem elaborado, o RH se preocupa em escolher bem os novos colaboradores

0 RH apenas cumpre tabela, fazendo um processo seletivo sem muita atenção

Não existe processo seletivo, existe indicação

Quanto ao processo seletivo da empresa $44,4 \%$ dos entrevistados dizem que o RH não tem papel atuante. $33,3 \%$ negam haver algum tipo de processo seletivo e 22,2\% alegam que o processo é bem elaborado pelo RH. 


\section{Na sua empresa existe pesquisa de clima e satisfação?}

9 respostas

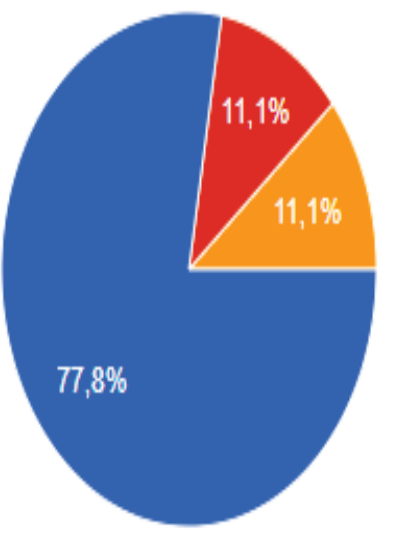

Não

Existe, porém as ações não são executadas

Sim, isso tem ajudado muito o clima organizacional

Em relação à pesquisa sobre clima organizacional e satisfação a grande maioria $(77,8 \%)$ alega não haver. $11,1 \%$ afirmam que ela existe, mas as ações não são executadas e $11,1 \%$ dizem que a pesquisa existe e que tem colaborado.

\section{Como você classifica o RH da sua empresa?}

9 respostas

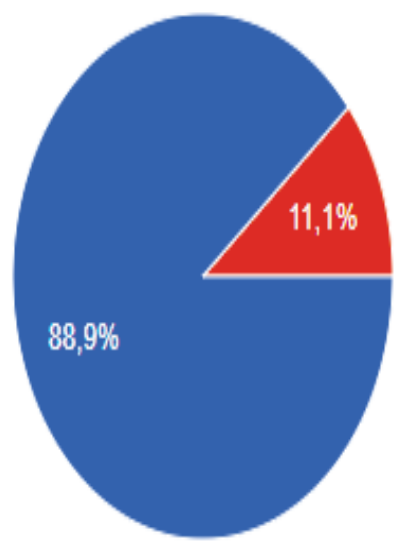

Só resolve assuntos burocraticos

Desenvolve um papel estrátegico na organização

A grande maioria $(88,9 \%)$ dos participantes desta pesquisa afirma que o setor de $\mathrm{RH}$ da empresa só resolve assuntos burocráticos. Apenas 11,1\% acreditam que o setor desenvolve papel estratégico na organização. 


\section{CONCLUSÃO}

Com base no resultado da pesquisa, conclui-se que a empresa analisada possui um quadro de colaboradores desmotivados com a falta de atuação do RH. Percebe-se que existem falhas nas atividades do setor em questão. Será necessário entender quais as dificuldades enfrentadas que impedem a realização das ações características de um RH estratégico.

Essa ausência de ação, sem dúvida, também impacta no resultado da empresa. Será necessária uma intervenção urgente para promover um clima organizacional harmonioso e reter talentos através de um plano de melhoria. As respostas dos voluntários da pesquisa mostram conhecimento por parte dos entrevistados sobre o papel do RH no mercado moderno, trazendo segurança para o diagnóstico mais assertivo do resultado obtido.

Nem sempre um clima organizacional negativo está atrelado ao setor de RH. A escolha errada na promoção ou admissão de novos líderes também pode trazer resultados insatisfatórios para a empresa. Como afirma James Hunter: "pegamos o melhor operador de empilhadeiras e transformamos no supervisor do depósito. Nessa hora, perdemos o melhor operador de empilhadeira e ganhamos um supervisor terrível” (HUNTER, 2015, p. 44).

Nessa citação, fica clara a importância da alta gestão analisar bem a sua equipe de líderes. Essa escolha não deve ser envolvida com emoção. É importante detectar o perfil de liderança ou o desenvolvimento desses futuros líderes. Quando essa análise não é feita, a responsabilidade das falhas não está no indivíduo promovido, mas na gestão que o promoveu. Com o objetivo de resolver essas questões, orienta-se que a empresa siga o plano de ação abaixo. Com essas ações a organização estará caminhando para um ambiente harmonioso, promovendo a isonomia da instituição.

1- Realizar pesquisa de clima organizacional;

2- Realizar Feedback da gestão com liderados e de liderados com a gestão;

3- Analisar resultados;

4- Detectar os desvios com base nos resultados;

5- Apresentar os resultados à alta gestão;

6- Realizar ações de melhoria e acompanhamento contínuo.

Conclui-se, portanto, que nos dias de hoje o gestor de Recursos Humanos não deixará de enfrentar desafios como em qualquer outra época. Os tempos mudam, os desafios também. Cabe ao gestor de RH ter a consciência de se aprimorar cada vez mais, estando sempre atento às mudanças que ocorrem não apenas no cenário organizacional, mas no mundo globalizado e 
em constante mudança. Não há dúvidas de que este profissional é e continuará sendo de fundamental importância para o progresso de qualquer instituição.

\section{REFERÊNCIAS}

CHIAVENATO, Idalberto. Gestão de Pessoas. 3. ed. Rio de Janeiro: Elsevier, 2010.

SCHIKMANN, Rodrigo Rennó. Administração geral para concursos. 2. ed. Rio de Janeiro: Elsevier, 2015.

HUNTER, James C. De volta ao mosteiro. Rio de Janeiro: Sextante, 2015.

OLIVEIRA, Joaquim. O que esperar do novo perfil do gestor de Recursos Humanos? Disponível em: https://www.rhportal.com.br/artigos-rh/o-que-esperar-do-novo-perfil-dogestor-de-recursos-humanos/. Acesso em: 12 out. 2020.

XERPA. Carreira em RH: descubra o segredo dos profissionais de sucesso. Disponível em: https://www.xerpa.com.br/blog/carreira-em-rh/. Acesso em: 20 set. 2020.

\section{Apêndice A - Plano de Ação}

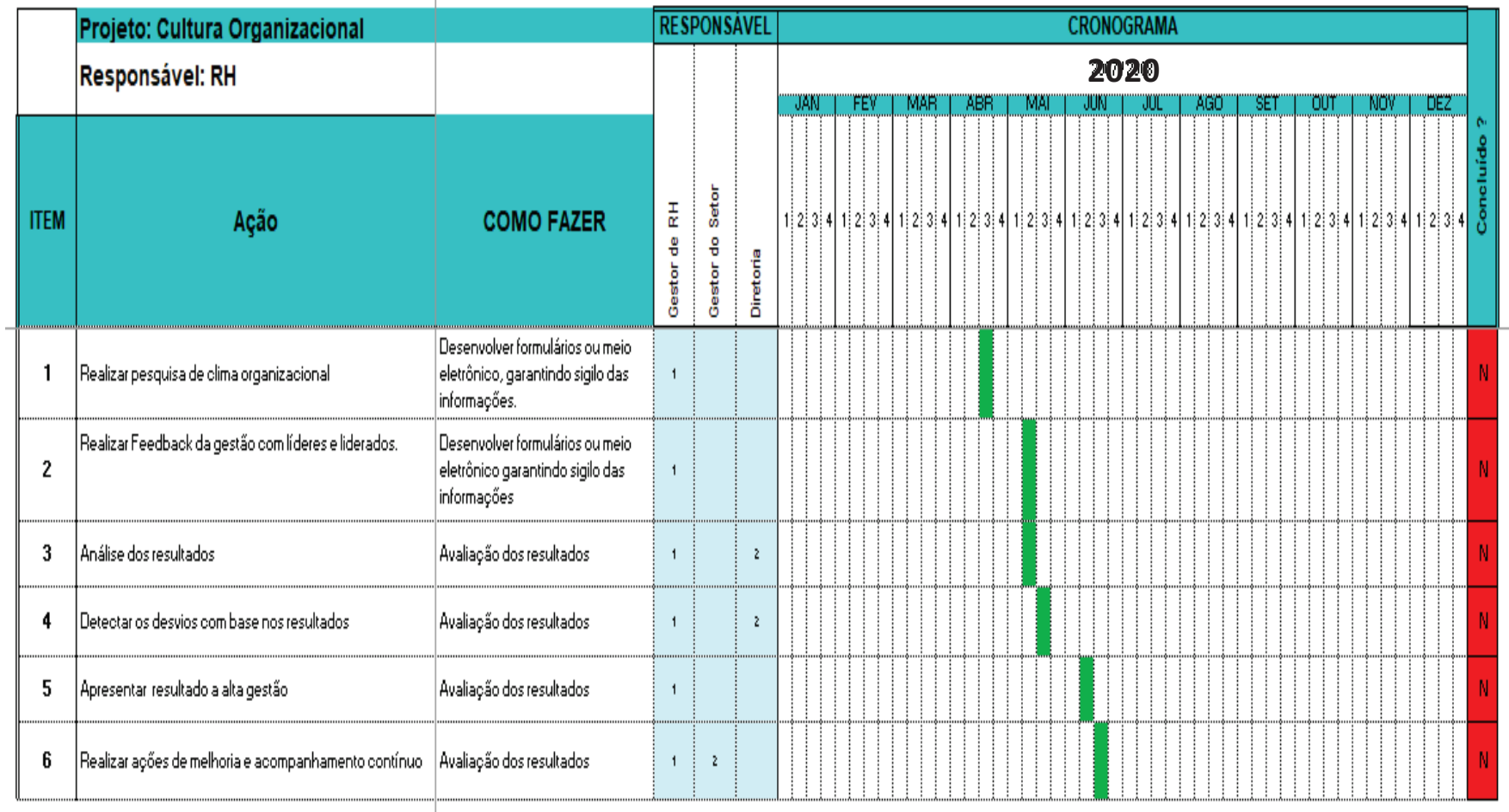

